\title{
Nilai Filosofis Peralatan Tradisional Terhadap Karakter Perempuan Jawa dalam Pandangan Masyarakat Pesisir Utara Jawa Tengah
}

\author{
M. Suryadi \\ Fakultas Ilmu Budaya, Universitas Diponegoro \\ mssuryadi07@gmail.com
}

\begin{abstract}
The uniqueness of Javanese society, especially the Javanese people north coast of Central Java is a way of looking at the values of life. One of the values of the life of the Javanese people is attached to traditional household appliances. Traditional tools have lexical meanings, cultural meanings, and philosophical values. These three components are captured in the name of the equipment. Traditional tools of coastal Javanese society gradually began to be abandoned by their owners and began to be replaced with modern equipment. As a result, inherent philosophical values begin to be forgotten. Research location in Demak Regency. Data collection methods used were observation, in-depth interviews, and focus group discussions.The data analysis method used is a description of the lexical component: the description of the lexical meaning and cultural meaning.Description of internal culture: elaboration of philosophical values.Research findings: each traditional equipment name has a correlation between the lexical meaning of cultural meaning, and cultural meaning of its philosophical value.The traditional equipment function of the coastal Javanese community is attached to referents. Philosophical values are attached to references.
\end{abstract}

Keywords: cultural, Java, lexical meaning, philosophical value, traditional equipment.

\section{Intisari}

Keunikan masyarakat Jawa, khususnya masyarakat Jawa pesisir utara Jawa Tengah adalah cara pandang terhadap nilai-nilai kehidupan. Salah satu nilai kehidupan masyarakat Jawa melekat pada peralatan rumah tangga tradisional. Peralatan tradisional memiliki arti leksikal, arti kultural, dan nilai filosofi. Ketiga komponen ini terpotret pada nama peralatan. Peralatan tradisional masyarakat Jawa pesisir lambat laun mulai ditinggalkan dan digantikan dengan peralatan modern, akibatnya nilai-nilai filosofi yang melekat mulai terlupakan. Lokasi penelitian di Kabupaten Demak. Metode pengumpulan data yang digunakan adalah observasi, wawancara mendalam, dan Fokus Group Diskusi. Metode analisis data yang digunakan adalah deskripsi komponen leksikal melalui penjabaran arti leksikal dan arti kultural. Metode internal budaya dilakukan untuk menjabarkan nilai filosofinya. Temuan penelitian adalah setiap nama peralatan tradisional memiliki korelasi antara arti leksikal terhadap arti kultural, dan arti kultural terhadap nilai filosofinya. Fungsi peralatan tradisional masyarakat Jawa pesisir melekat pada referent dan nilai filosofi melekat pada reference.

Kata kunci: arti leksikal, Jawa, kultural, nilai filosofi, peralatan tradisional 


\section{Pendahuluan}

Masyarakat Jawa memiliki multi budaya, baik budaya yang terkait dengan rasa, perilaku, tatanan, gedung, maupun peralatan. Budaya sebagai inti hakiki sebuah masyarakat memiliki nilai-nilai luhur yang dianut oleh masyarakatnya. Keluhuran budi dan bahasa sebagai potret utama dalam berperilaku. Keagungan gedung atau bangunan dan peralatan sebagai potret fisik kemajuan peradaban dan kecerdasan.

Masyarakat Jawa, khususnya masyarakat pesisir utara Jawa Tengah memiliki budaya yang unik. Keunikan ini sebagai hasil perkembangan dan kedinamisan budaya Jawa di wilayah sentra. Keunikan lingual tersebut dapat ditilik melalui bahasa dan dialeknya, keunikan perilaku dapat ditilik melalui adatradisi, dan keunikan fisik dapat ditilik salah satunya melalui peralatan rumah tangga tradisional.

Peralatan rumah tangga tradisional adalah seperangkat peralatan yang digunakan untuk memenuhi hajat hidup manusia Jawa pada bidang pangan, sandang, dan tempat tinggal. Peralatan di bidang pangan meliputi semua peralatan yang digunakan untuk menyimpan, mengolah, dan menghidangkan semua kebutuhan pokok manusia Jawa. Peralatan ini dapat berupa perkakas rumah tangga, yakni perkakas rumah tangga tradisional. Perkakas ini kerapkali diletakkan dan digunakan dalam pawon 'dapur'. Peralatan rumah tangga tradisional proses pembuatannya menggunakan keterampilan manual dengan bahan dasar alam: tumbuhan, tanah, kulit binatang. Fenomena terkait peralatan tradisional ini adalah keterkaitan baik secara implisit maupun eksplisit antara nama-konsep-referent yang dimiliki alat-alat tersebut. Fenomena lain adalah alat tradisional ini mulai ditinggalkan dan digantikan dengan peralatan lebih modern. Berangkat dari kedua fenomena tersebut, rumusan masalah yang diangkat dalam penelitian ini adalah bagaimana korelasi antara nama identitas peralatan dengan konsep dan referentnya; dan bagaimana nilai filosofi yang melekat pada peralatan tradisional sebagai kecerdasan dan kearifan lokal masyarakat Jawa pesisir utara Jawa tengah.

Sumber rujukan penelitian yang digunakan sebagai pemertajam teori dan analisis adalah sumber ilmiah yang memiliki kegayutan dengan penelitian, antara lain memiliki topik, sebagai berikut: etika dan budaya Jawa, teori semantic terkait arti leksikal dan gramatikal, nilai filosofi pada masyarakat Jawa. 
Sugiyanto (2015) menyoroti budaya Jawa melalui pakian adat yang dipakai oleh masyarakatnya. Pakian adat adalah sebuah identitas suatu daerah dan sekaligus sebagai symbol yang dimiliki masyarakatnya. Lokasi penlitian berada di wilayah Ponorogo. Ponorogo dianggap memiliki pakian khas Warok Ponorogo. Pakian ini memiliki nilainilai filosofi sekaligus cerminan karakter masyarakatnya. Nilai filosofis yang diangkat adalah keberanian, kesabaran, dan ketenangan. Penelitian ini dimanfaatkan karena terkait dengan kearifan lokal yang tercermin pakian adat, sebagai salah satu unsur ekspresi nilai budaya.

Wortham (2008)memotret ekspresi budaya yang terait dengan perilaku. Perilaku yang dibidik adalah tuturan lingual perempuan memiliki gradasi kesantunan lebih eksplisit dibandingkan laki-laki. Perempuan lebih jelas dalam mengekspresikannya. Hasil penelitian ini dimanfaatkan terkait dengan ekspresi budaya pada perempuan. Perempuan selalu terkait pula dengan peralatan tradisional. Diharapkan peran perempuan dalam mengekspresikan budaya dapat diukur lebih jelas.

(Purbasari and Putri (2015) melalukan penelitian dengan fokus pemilahan peran dalam kehidupan keluarga Jawa. Dalam kehidupan keluarga Jawa ada tiga peran pokok, yakni peran pengambilan keputusan (perpihak pada laki-laki). Peran kelola keuangan (perpihak pada perempuan). Peran asuh anak (perpihak pada perempuan). Peran-peran tersebut diupaya terjaga dengan melakukan prinsip kerukunan. Penelitian ini dimanfaatkan bahwa dalam rumah tangga Jawa, ekpresi budaya rukun menjadi pilihan utama dalam mengendalikan kehidupan dalam berumah tangga.

Sarolangun et al. (2014) melakukan penelitian pada kehidupanmasyarakat pedalaman di hutan Jambi. Fokus penelitian pada kemampuan dalam membuat peralatan rumah tangga tradisional. Hasil penelitian antara lain identifikasi jenis-jenis peralatan rumah tangga dan cara pembuatan peralatan rumah tangga. Penelitian ini menjadi rujukan penelitian karena melibatkan jenis dan fungsi peralatan rumah tangga.

Ogden and Sandulescu (2013) teori semantic terkait The Meaning of Meaning a Study of the Influence of Language upon Thought and of the Science of Symbolismdigunakan dalam penelitian ini, terutama untuk mendeskripsikan pertalian word-consept-referent. 


\section{Metode Penelitian}

Lokasi penelitian berada di Kabupaten Demak sebagai ciri salah satu masyarakat Jawa Pesisir utara Jawa Tengah. Jenis penelitian ini adalah penelitian kualitatif, yang lebih menutamakan pada fenomena lingual yang tercermin pada peralatan rumah tangga tradisional. Ancangan penelitian yang digunakan linguistik deskriptif. Konsep teori yang digunakan meaning of meaning(Ogden and Sandulescu 2013) dengan mempertimbangkan sosikultural masyarakat Jawa Pesisir(Suseno 1984) dan (Sudaryanto 1989).

Data dalam penelitian ini meliputi data primer dan data sekunder. Data sekunder digunakan untuk mendukung data primer. Pengumpulannya dilakukan dengan menggunakan metode observasi, interviu (structured interview dan in-depth interview), dan focus grop discussion.

Metode analisis data yang digunakan adalah deskripsi komponen leksikal melalui penjabaran arti leksikal dan arti kultural. Metode internal budaya dilakukan untuk menjabarkan nilai filosofinyametode padan dengan memperhatikan watak data itu sendiri(Duranti 2012) dan (Johnson, Fox, and King 2004).

\section{Pembahasan}

Filosofi bagian dari kerangka pikir manusia secara kritis untuk memperoleh penyelesaian sebuah persoalan secara imbang. Semua yang dipikirkan berangkat dari prinsip kebijakan atau kepatutan. Hasil yang diperoleh tidak ada yang dirugikan dan memiliki nilai manfaat yang cukup tinggi. Kemanfaatan yang diperoleh punselalu memiliki keselarasan dengan alam.

Masyarakat Jawa memiliki nilai filosofis yang tinggi. Nilai filosofisnya selalu diukur dengan keseimbangan dan keselarasan. Filosofi Jawa terkait dengan budi-etikasosial-alam. Budi terkait dengan rasa. Etika terkait dengan pergaulan. Sosial terkait dengan masyarakat. Alam terkait dengan semesta. Semua komponen ini akandipertimbangkan untuk mencapai keseimbangan, semata-mata untuk meraih keluhuran dan ketentraman hidup. Tercermin dalam ungkapan eling lan waspada.

Nilai filosofis masyarakat Jawa yang mencerminkan kehati-hatian dan keseimbangan dengan alam, antara lain sebagai berikut.

1) Sura dira Jayaningrat, lebur dening pangastuti 'segala sifat keras hati, angkara murka 
hanya bisa dileburkan dengan sikap lemah lembut dan kesabaran.

2) Memayu hayuning bawana ambrasta dur hangkara 'hidup didunia mengutakan keselamatan, kebahagian, kesejahteraan serta memberantas sifat angkara murka, serakah, dan tamak.

3) Urip iku urup 'hidup harus dapat memberi manfaat orang lain.

4) Aja gumunan, aja getunan, aja kagetan, aja aleman 'tidak mudah heran, tidak mudah menyesal, tidak mudah terkejut, dan tidak manja',

5) Ngluruk tanpabala menang tanpa ngasorake sekti tanpa aji-aji lan sugih tanpa banda 'berjuang tanpa bala, menang tanpa merendahkan orang lain, berwibawa tanpa kekuasaan, dan kaya tanpa harta.

\section{Tatanan Rumah Tangga Jawa}

Tatanan rumah tangga masyarakat Jawa cenderung menganut sistem patriarki. Sistem ini menempatkan sosok laki-laki sebagai pemegang kekuasaan dalam kehidupan berumah tangga. Dalam tatanan rumah tangga Jawa, sosok ayah memiliki otoritas terhadap isteri dan anak-anak. Posisi ini berdampak bahwa perempuan Jawa selalu terikat oleh berbagai tata aturan dan tatakrama kehidupan.

Pandangan ini secara serta-merta mengikat sosok perempuan harus menjadi isteri yang baik. Batasan isteri yang baik tidak dapat dilepaskan sebagai sosok yang penurut, setia, lemah lembut, dan inferior. Peran perempuan Jawa hanya berkisar pada peran domistik rumah tangga. Laki-laki memiliki peran utama untuk memutuskan sedangkan perempuan kurang memiliki peran dalam mengambil keputusan. Posisi ini tidak sesuai dengan UU No. 7 tahun 1984 tentang ratifikasi Convention on The Elimination of All Forms of Discrimanation Against Women(RI 1984).

Tatanan kehidupan masyarakat Jawa akibat warisan budaya priyayi kerapkali memposisikan perempuan sebagai pelengkap (bandingkan ajaran wulangreh), bahwa kodrat perempuan haruslah meluhurkan suami. Mengangkat harkat suami adalah kewajiban bagi perempuan yang berstatus isteri. Apakah konsep pandangan ini memiliki kegayutan terhadap konsep-konsep yang melekat dalam peralatan rumah tangga yang lekat dengan sosok perempuan. Atau justru konsep yang melekat dalam peralatan tersebut menggugurkan konsep patriarki, yang sengaja dilegitimasikan untuk menguatkan kedudukan laki-laki dalam tatanan rumah tangga. 


\section{Karakter Perempuan Jawa dalam Pandangan Masyarakat Jawa}

Konsep perempuan Jawa dalam pandangan masyarakat Jawa memilikilimakarakter utama. Adapun lima karakter tersebut ayu, lembut, kuat, empati, dan mesra. Karakter ayu yang dapat dimaknai cantik. Cantik secara fisikal maupun cantik secara batiniah. Cantik fisikal terbatas pada paras wajah dan tubuh yang seimbang. Cantik batiniah terkait dengan tabiat dan watak, termasuk di dalamnya perilaku dalam keseharian.

Karakter lembut terkait dengan tindak tutur. Tindak tutur akanmengangkat harkat dan kesantunan sebagai pribadi Jawa. Setiap apa yang dituturkan tidak dapat dilepaskan dengan tingkat tutur. Lembut bertutur memiliki makna lembut dalam isidan pesan.

Karakter kuat dimaknai sebagai kekuatan menahan beban kehidupan. Beban kehidupan dapat dijabarkan semua butir kehidupan rumah tangga, baik berupa fisik maupun batin. Beban fisik dikaitkan dengan materi. Beban batin dikaitkan dengan keluhandan sayang. Perempuan Jawa dapat dikategorikan sebagai wonder women karena dapatmerantasi semua kehidupan rumah tangga, baik berperan sebagai pilar ekonomi maupun pilar kasih sayang.

Karakter empati dikaitkan dengan perasaan afektif. Perempuan Jawa memiliki keinginan untuk menolong sesamanya. Kekuatan melebur untuk menolong orang lain sangat tinggi, memiliki keterlibatan rasa terhadap apa yang dirasakan orang lain. Bentuk empati ini lahir dari rasa kasih sayang seorang perempuan Jawa terhadap lingkungannya.

Karakter mesra dikaitkan dengan hubungan persona. Seorang perempuan Jawa selalu setia dan kukuh terhadap pasangannya. Pandai menempatkan diri sebagai isteri sekaligus sebagai seorang ibu. Kekuatan kemesraan ini lah yang membuat teduh kehidupan rumah tangga. Sebagai kekuatan pilar hubungan kasih sayang dalam tatanan rumah tangga.

\section{Konsep Peralatan Tradisional bagi Masyarakat Jawa}

Konsep atau reference tidak dapat dipisahkan dengan nilai-nilai budaya yang hidup di mana bahasa tersebut digunakan. Bahasa sebagai hasil ekspresi dari nilai-nilai budaya, baik langsung maupun tidak langsung. Hasil ekspresi tersebut dapat abstrak dan konkrit. Ekspresi abstrak dapat berwujud perasaan, gagasan, dan olah budi. Ekspresi konkrit dapat 
berwujud kebiasan, perilaku, dan hasil karya. Hubungan tersebut memiliki relativitas yang tergantung pada ruang dan waktu.

Hubungan bentuk terhadap konsep, hubungan konsep terhadap referent, dan hubungan bentuk terhadap referent memiliki relativitas yang berbeda-beda. Hubungan bentuk terhadap konsep (reference) memiliki hubungan langsung. Hubungan tersebut mengisyaratkan bahwa setiap penamaan sebuah benda memiliki keterkaitan dengan konsepnya meskipun kadangkala konsep tersebut memiliki hubungan arbiter terhadap referentnya, tergantung ruang dimana konsep tersebut digunakan, berakar kembali dengan nilai budaya yang hidup dan berkembang. (Wiiliam Foley 2012)menyebutkan The concept of meaning is absolutely fundamendal to te filed 'konsep sebuah makna mutlak bergantung pada keadaan lingkungan sekitarnya. Dengan demikian, konsep peralatan tradisional berada pada hubungan antara form-reference-referent. Untuk mengkaji persoalan ini, maka peran utama berada pada tataran meaning atau arti. Arti pada tataran ini dibedaka atas arti leksikal, arti kultural dan arti filosofi.

Arti leksikal adalah arti yang melekat secara utuh pada kata itu sendiri dan terbebas dari konteks. Arti leksikal melekat secara otonom baik sebagai simbol maupun sebagai identitas. Dengan demikian, arti leksikal adalah arti yang sebanarnya, biasa melekat pada arti kamus.

Arti kultural adalah arti yang dibangun dengan memanfaatkan nilai-nilai budaya yang tumbuh di masyarakat. Nilai budaya dapat berupa rentetan simbol, alur historis, tata kebiasaan, dan peristiwa. Arti kultural dapat juga sebagai hasil simbiosis antarsimbol. Arti kultural pun dapat dihasilkan dari cara pandang masyarakat terhadap peristiwa atau fenomena luhur.

Arti filosofi adalah arti yang kritis, sebagai hasil pemikiran kritis. Hakikat dari filosofi adalah kebijaksanaan, kearifan, dan kerendahan hati. Arti filosofi selalu berada dibalik arti leksikal dan arti kultural. Arti filosofi dapat juga diberikan batasan sebagai arti di dalam arti.

\section{Nilai Filosofis Peralatan Rumah Tangga Tradisional}

Nilai filosofissangat tergantung padacara pandang masyarakat dalam memaknai peristiwa atau fenomena yang tumbuh berkembang dalam masyarakat itu sendiri. Nilai filosofis 
dihasilkan melalui olah daya pikir, daya rasa,dan kekuatan perilaku dalam sebuah peristiwa. Yang dihasilkan melalui turun menurun pada alur pewarisan budaya. Nilai filosofis mencakup satu kesatuan dari arti leksikal dan arti kultural yang melebur menjadi satu dengan tambahan nilai budaya.

Konsep dan nilai filosofis peralatan rumah tangga tradisional tercermin dari bagian-bagian peralatan tersebut. Peralatan rumah tangga tradisional sebagai hasil nilai budaya yang berupa hasil karya atau olah pekerjaan atau ekspresi budaya konkrit. Ekspresi budaya sebagai hasil karya luhur sejarah manusia masyarakat Jawa, keberadaannya mulai redup, mulai ditinggalkan dan mulai digantikan peralatan modern yang cenderung praktis. Adapun ekspresi budaya berwujud peralatan tradisional deskripsikan di bawah ini, sebagai berikut.

\section{Gentong}

Gentong adalah ekspresi budaya yang memiliki arti leksikaltempat menampung air bersih, terbuat dari tanah liat, dan proses pembuatan melalui pencetakan dan pembakaran. Dalam Kamus Bahasa Jawa Bau Sastra(2001:233) diartikan sebagai wadhah banyu gedhe saemper genuk (digawe saka lemah lempung dicithak banjur diobong. Arti kata gentong berkait langsung dengan konsep penyimpan air. Air yang disimpan adalah air kehidupan, air bersih dan jernih diambil dari sumur atau mata air.

Arti kultural leksikon gentong dapat diperikan berdasarkan wujud fisiknya. Gentongdibuat dari tanah liat pilihan yang diolah dengan keuletan dan ketekunan. Olahan tanah tersebut selanjutnya dibakar dengan bahan bakar kayu dan sekam. Pembakaran ini untuk kematangan olahan tanah. Bentuk fisik gentong adalah memiliki lubang di atas yang disebut lambe 'bibir' berbentuk bulat, disambung dengan leher yang ukurannya lebih menyempit dari lambe gentong 'bibir gentong'. Fisik selanjutnya adalah badan gentong dan pantat gentong. Badan gentong ukurannya lebih besar dan gembung. Sedang pantat gentong ukurannya lebih kecil, besar ukuran lingkaran sama dengan ukuran lehar gentong.

Berdasarkan deskripsi fisik gentong maka arti kultural gentong adalah tempat menyimpan air kehidupan untuk kehidupan masyarakat Jawa. Sebagai tempat penyimpanan air kehidupan. Air kehidupan harus tersimpan rapi dan harus dihemat penggunaannya. Unsur kehematan memiliki proyeksi bahwa sebuah keluarga dianggap 
sejahtera bila gentong air itu selalu berisi penuh. Gentong air yang selalu berisi air penuh sebagai representasi kemakmuran sebuah keluarga.Gentong sebagai peralatan rumah tangga tradisional sebagai potret bank atau tempat tabungan sebuah keluarga.

Nilai filosofis peralatan rumah tangga tradisional gentong adalah simbol kesejahteraan kehidupan rumah tangga. Semakin berisi gentong dalam rumah tangga semakin sejahtera kehidupan rumah tangga tersebut. Kesejahteraan dalam kehidupan rumah tangga Jawa salah satu parameternya adalah menggunakan simbol gentong, yakni kemampuan menyimpan air dan penghematan penggunaan air.

\section{Cetingatau Boboko}

Leksikon ceting secara leksikal memiliki arti wadhah sega 'tempat nasi' (Kamus Bahasa Jawa Bau Sastra, 2001:111). Dalam masyarakat Jawa, ceting digunakan untuk menyimpan olahan matangmakanan pokok, dapat berupa nasi beras, nasi jagung, dan umbi-umbian. Leksikon ceting memiliki kiratabasa cemepake barang ingkang penting'sebagai tempat atau wadah barang yang penting'.

Ceting dalam masyarakat Jawa terbuat dari anyaman kulit bambu dengan ukuran bervariasi $(15-25 \mathrm{~cm})$. Ukuran atas lebih besar dibandingkan ukuran dasar. Bagian atas disebut dengan lambe 'bibir' ceting dengan diberi ring bamboo, alur anyaman mengarah ke dalam. Bagian dasar ceting ditopang dengan dudukan bambu berbentuk segi empat. Dudukan ini memiliki tiga fungsi, pertama menopang ceting, kedua tempat sirkulasi udara supaya nasi dapat pulen, ketiga sebagai alat resapan air sehingga nasi bisa tahan lebih lama dan tidak mudah basi.

Ceting memiliki arti kultural sebagai cemepake barang sing penting 'tempat atau wadah untuk barang yang penting bagi kehidupan (nasi)'. Arti kultural yang melekat pada ceting adalah tempat utama atau tempat penting bagi keluarga Jawa sebagai simbol kecukupan kebutuhan dasar. Ceting harus dijaga agar tidak kosong. Ceting yang berisi menandakan kehidupan yang serba cukup. Sehingga muncul ungkapan mergeawe sing temen ben cetinge ora guling 'bekerjalah yang optimal agar kehidupan mu tidak rapuh'.

Nilai filosofisceting dalam kehidupan rumah tangga Jawa adalah simbol kecukupan dan ketentraman keluarga. Kecukupan ditandai dengan tersedianya kebutuhan 
makanan pokok sega 'nasi'. Ceting ditopang dengan empat dudukan, yang mengisyaratkan empat komponen, yakni:

1) Mergawe sing temen 'bekerja dengan optimal'.

2) Nerima ing hasil 'meneima hasilnya'.

3) Dicakke kanthi syukur 'dihidangkan dengan rasa syukur'.

4) Didhum kanthi rata 'digunakan bersama dalam keluarga'.

Ungkapan ceting ora entuk ngguling lan ora entuk garingnilai filosofis ungkapan ini adalah kebutuhan pokok dalam keluarga adalah ketersedian nasi sebagai sumber kekuatan, sehingga tidak boleh ada perut kosong agar tidak terjadi ketimpangan. timpang.

\section{Dunak}

Dunak memiliki arti wadah atau tempat menampung bahan kebutuhan pokok. Dunak terbuat dari anyaman kulit atau daging kulit bambu. Bentuk visualnya terdiri atas: bagian atas adalah mulut dunak berbentuk lingkaran, bagian dasar berbentuk segi empat memiliki ukurannya lebih kecil. Dunak kerapkali digunakan untuk sarana membawa hasil kebun dari lading menuju rumah atau menuju pasar untuk dijual. Dunak memiliki ukuran lebih besar agar mampu membawa hasil panen kebun. Dunak dapat dibawa dengan caradisunggi di atas kepala, digendong dengan selandang di belakang punggung, dan dengan cara dipikul pada pundak.

Dunak memeliki arti kultural $\underline{\boldsymbol{d u}}$ dahane barang enak 'bila dibongkar isinya barang yang enak-enak'. Dunak sebagai simbol alat untuk membawa bahan-bahan yang memiliki nilai ekonomis, baik untuk diri keluarga maupun untuk dijual. Maksud barang enak adalah semua barang yang memiliki nilai ekonomis, baik dari sisi kuantitas maupun kualitas. Nilai filosofis leksikon dunak adalah bila menempatkan sesuatu sesuai dengan tempatnya dan sebaik mungkin. Kata sebaik mungkin memiliki multi maksud, yakni baik tempatnya, baik cara menyimpannya, dan baik cara membawanya. Kalau yang dibawa hanya sebuah maka dunakakan dibawa dengan cara disunggi atau digendong. Bila yang dibawa dua dunak maka dunak akan dipikul dibahu. Setiap membawa dunak selalu menggunakan kedua tangan. Simbol inipun memberikan filosofi bahwa sesuatu yang utama harus diterima atau disambut dengan kedua tangannya sebagai bentuk syukur.

\section{Simpulan}


Hasil analisis kajian "Nilai Filosofis Peralatan Tradisional terhadap Karakter Perempuan Jawa dalam Pandangan Masyarakat Jawa Pesisir" mengungkap korelasi antara nama identitas peralatan dengan konsep dan referentnya sekaligus mengangkat nilai filosofis yang melekat pada peralatan tradisional.

Temuan penelitian ini adalah setiap nama peralatan tradisional memiliki korelasi antara arti leksikal terhadap arti kultural, dan arti kultural terhadap nilai filosofinya. Khusus korelasi antara nama identitas peralatan tradisional terhadap konsepnya bersifat langsung, sedangkan korelasi antara nama peralatan tradisonal terhadap referentnya bersifat arbiter, tergantung atas ruang atau wilayahnya. Nilai filosofis peralatan tradisional melekat pada reference.

\section{Daftar Pustaka}

Duranti, Alessandro. 2012. "Anthropology and Linguistics." Pp. 42-55 in The SAGE Handbook of Social Anthropology.

Johnson, Helen, Richard G. Fox, and Barbara J. King. 2004. "Anthropology beyond Culture." Anthropologica 46(1):108-9.

Ogden, C. K. and C. George Sandulescu. 2013. The Meaning of Meaning A Study of the Influence of Language upon Thought and of the Science of Symbolism. edited by C. G. S. Recom. Monte Carlo.

Purbasari, Dyah and Kusumaning Putri. 2015. "PEMBAGIAN PERAN DALAM RUMAH TANGGA." 16(1):72-85.

RI, UU. 1984. "( Convention on the Elimination of All Forms of Discrimination Against." (3):1979-81.

Sarolangun, Park, Dwi Mairida, Bambang Hariyadi, Fachruddin Saudagar, Studi Pendidikan Biologi, Fkip Universitas Jambi, Jl Jambi, and Muara Bulian. 2014. "Kajian Etnobotani Peralatan Rumah Tangga Suku Anak Dalam Di Taman Nasional Bukit Dua Belas Kabupaten Sarolangun, Jambi.” 7(2).

Sudaryanto. 1989. Pemanfaatan Potensi Bahasa: Kumpulan Karangan Sekitar Dan Tentang Satuan Lingual Bahasa Jawa Yang Berdaya Sentuh Inderawi (Seri ILDEP). yogyakarta: Kanisius Publishing.

Sugiyanto, Alip. 2015. "Kajian Etnolinguistik Terhadap Pakaian Adat Warok Ponorogo." Aristo 3(1):19-27.

Suseno, Franz Magnis. 1984. Etika Jawa: Sebuah Analisa Falsafi Tentang Kebijaksanaan Hidup Jawa. Jakarta: Gramedia Pustaka Utama.

Wiiliam Foley. 2012. Anthropological Linguistics. Massachutts USA : Blackwell Publishers. 
Wortham, Stanton. 2008. "Linguistic Anthropology." Pp. 83-97 in The Handbook of Educational Linguistics. 